coastal development are available, and this gap should be remedied well before most areas are built up, mangroves cut down, swamps and lagoons "reclaimed", and coral reefs destroyed."

Summing up, Professor McIntyre said: 'Too little attention is being paid to the consequences of coastal development and land-based activities for the oceans. Especially if you consider the continuing population growth, there is good reason to fear a significant deterioration in the marine environment in the next decade... unless strong, coordinated national and international action is taken now. There must be concerted measures to conserve raw materials and to reduce wastes. This will call for great efforts and involve high costs, but nothing less will ensure the continued health of the oceans.'

In addition to UNEP, other GESAMP-sponsoring organizations are the UN Food and Agriculture Organization, the International Atomic Energy Agency, the International Maritime Organization, UNESCO, the United Nations, the World Health Organization, and the World Meteorological Organization.

Paul Evan Ress, Consultant 19 Avenue de Budé 1202 Geneva, Switzerland.

\title{
BTCV and the Natural Break
}

In Environmental Conservation Vol. 15, No. 4, p. 372 , Winter 1988, Anita Prosser described the initiative that is being taken by the British Trust for Conservation Volunteers (BTCV) to inculcate the idea of local, unpaid involvement in conservation work in as many countries as are prepared to take steps to set up similar organizations. BTCV is also recruiting volunteers to work with local groups in countries of the European Community (EC), the aim being to introduce the 'volunteering ethic' where this is not, as yet, a strong feature of public life.

In the United Kingdom the Trust, which was founded 30 years ago as the Conservation Corps, with fewer than 50 members, has expanded and developed into an organization for which over 60,000 volunteers worked on a wide variety of projects during the course of the last twelve months. Activities range from a single Sunday's pine-pulling*, or a weekend spent clearing refuse from the tidal mud-flats of the River Thames, to fully residential working holidays_- The Natural Break'. In addition, BTCV runs programmes for schools (often giving children in the inner cities their first introduction to the natural world) and 750 training courses for group leaders and others interested in woodland and country skills.

The Trust publishes a number of handbooks on these crafts, as well as books for schools, a Tree and Shrub catalogue, and its quarterly newsletter, 'The Conserver'

\footnotetext{
*Apparently this means "pulling up young pines that are thought to be alien or intrusive in a particular area'. - Ed.

†Wondering about the size of this figure, we asked the Author, who replied (in litt.) 'this figure was erring on the side of caution' as the figure usually given is $15,000,000$, but 'Just to make sure I rang the Nature Conservancy Council and they said "Forestry Commission's accepted figure is $15,000,000^{\circ}$ '.'-Ed.
}

(all on recycled paper). Following, although not entirely as a consequence of, the great storm of October 1987, in which more than $14,000,000$ trees $\dagger$, mainly in the south and south-east of England, were estimated as having been destroyed in a single night, BTCV launched a campaign to plant $1,000,000$ trees. By October 1989 , when the campaign had run for twelve months, 385,543 trees had been planted by 25,000 volunteers.

BTCV possesses no land, but does own a number of volunteer and training centres; these are very often disused farm buildings which have been repaired and converted by volunteers. Eight hundred and seventy-five schools and 580 local groups are affiliated with BTCV, and the Trust now has its own Appeal Department. BTCV is employed by local authorities, National Parks, the National Trust, Water Authorities, many other staturory and volunteer bodies, and farmers and private landowners - all of whom pay the Trust for the work that is carried out in their interest. Sponsorship comes from industry, "central Government, the Countryside Commission, charitable trusts, etc.

Anita Prosser, the BTCV International Development Officer, can be contacted at the Trust's Headquarters: 36 St Mary's Street, Wallingford, Oxfordshire, OX10 0EU. She would be pleased to provide further information and to give every assistance to anyone aspiring to set up a similar organization outside the UK, which it is hoped in time more and more will do.

CHRISTINE MARSH
192 Peperharow Road
Godalming
Surrey GU 7 PS
England, UK.

\section{Towards a Greener Europe}

The British Trust for Conservation Volunteers (BTVC) is widening its action to involve more and more other Europeans in the direct care and management of their local environments, as exemplified in the account published over a year ago in Environmental Conservation (Vol. 15, No. 4, p. 372 with fig., Winter 1988). For thirty years, BTCV has been helping to conserve the UK environment with the support, duly organized, of tens of thousands of volunteers.* During the past year alone more than 50,000 people helped to save some of the country's most valued wildlife habitats and traditional

*Let us express the hope that their attractive emblem (of a palmate green leaf dominating the acronym) will become well-known and be proudly worn by all concerned as a gentle reminder that much can be done to safeguard our own and Nature's environment. - Ed. landscapes, and now conservation organizations throughout Europe will be able to draw on this expertise through a unique new network.

The International Conservation Action Network (ICAN) is funded by the European Commission and aims to help European conservation organizations to involve local people by providing information about working with volunteers; setting up practical projects; working with local communities; advising on habitat management techniques; and organizing training courses and seminars.

The first example of ICAN was launched in Lille, France, in November 1989 with the creation of Vert Bizness - an exciting new scheme to involve French students from technical colleges in setting up 'green' business ventures. BTCV's contribution to Vert Bizness will be principally through the provision of practical sup- 